\title{
TEMPERATURE CHANGES IN POLAND IN 21ST CENTURY - RESULTS OF GLOBAL SIMULATION AND REGIONAL DOWNSCALING
}

\author{
Michą Pilarski \\ Institute of Geography, University of Gdańsk, Poland \\ Manuscript received: October 29, 2014 \\ Revised version: July 22, 2015
}

PILARSKI, M., 2015. Temperature changes in Poland in 21st century - results of global simulation and regional downscaling. Quaestiones Geographicae 34(3), Bogucki Wydawnictwo Naukowe, Poznań, pp. 85-99, 12 figs, 1 table. DOI 10.1515/quageo-2015-0023, ISSN 0137-477X.

\begin{abstract}
The main source of information about future climate changes are the results of numerical simulations performed in scientific institutions around the world. Present projections from global circulation models (GCMs) are too coarse and are only usefulness for the world, hemisphere or continent spatial analysis. The low horizontal resolution of global models (100-200 km), does not allow to assess climate changes at regional or local scales. Therefore it is necessary to lead studies concerning how to detail the GCMs information. The problem of information transfer from the GCMs to higher spatial scale solve: dynamical and statistical downscaling. The dynamical downscaling method based on "nesting" global information in a regional models (RCMs), which solve the equations of motion and the thermodynamic laws in a small spatial scale (10-50 km). However, the statistical downscaling models (SDMs) identify the relationship between large-scale variable (predictor) and small-scale variable (predictand) implementing linear regression. The main goal of the study was to compare the global model scenarios of thermal condition in Poland in XXI century with the more accurate statistical and dynamical regional models outcomes. Generally studies confirmed usefulness of statistical downscaling to detail information from GCMs. Basic results present that regional models captured local aspects of thermal conditions variability especially in coastal zone.
\end{abstract}

Keywords: downscaling, climate changes, air temperature, canonical correlation analysis, weather generator, Poland

Address of the corresponding author: Michat Pilarski, Institute of Geography, University of Gdańsk, 80-952 Gdańsk, Poland; e-mail:michpil@gmail.com

\section{Introduction}

According to the IPCC AR4* (Fourth Assessment Report of the Intergovernmental Panel on Climate Change) global average temperature has increased of $0.74^{\circ} \mathrm{C}$ since the beginning of the twentieth century to the early 21st century (1906-2005). This trend is higher than the cor-

* All works in the study have been conducting in 2012/13. New IPCC report (AR5 - Fifth Assessment Report) results have been available since January 2014 in the final version. The paper does not include new results from AR5 although the article was submitted in 2015. responding trend of $0.60^{\circ} \mathrm{C}$ given in the previous IPCC TAR (Third Assessment Report of the Intergovernmental Panel on Climate Change (1901-2000) (Core Writing Team, Pachauri and Reisinger 2007). Present projections of climate change from the global simulations (GCMs) estimate of global temperature anomalies at the end of the twenty-first century, ranging from $1^{\circ} \mathrm{C}$ to $6^{\circ} \mathrm{C}$ (depending on the storylines of greenhouse gas emissions). GCMs results unambiguously indicate on a faster temperature rise as compared to the previous age, especially in the global land areas and high latitudes of the northern hem- 


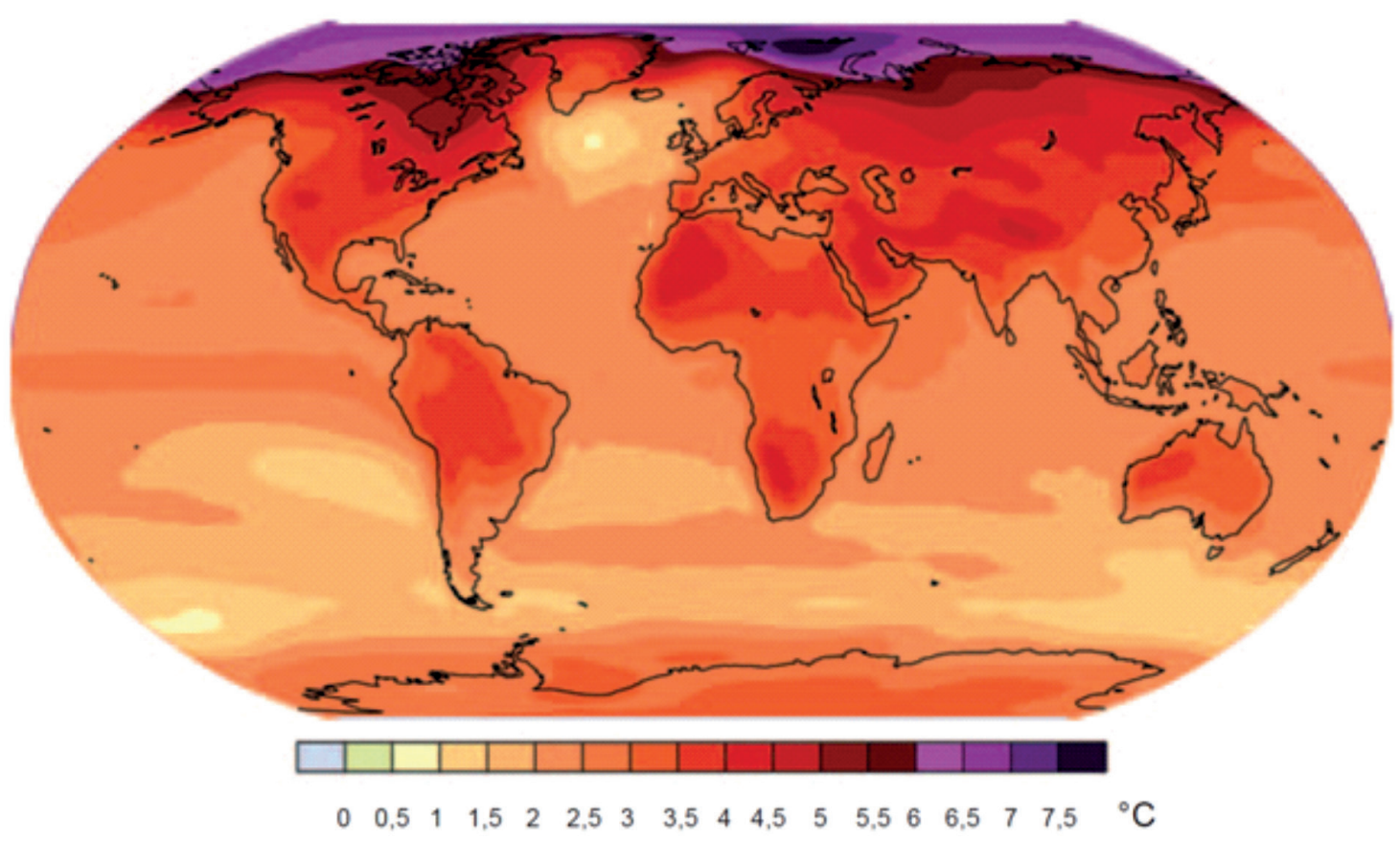

Fig. 1. Anomalies of air temperature at the end of 21st century (2090-2099) in relation to 1980-1999 from several Atmosphere-Ocean Coupled General Circulation Models (AOGCMs) for A1B emission scenario. Source: IPCC AR4.

isphere (Fig. 1). However, the usefulness of the results of global models in terms of urban planning, impact studies, mitigation and adaptation strategies etc. in the regional and local scale is not sufficient (Mearns et al. 2003). This is mainly caused by coarse spatial resolution of global models (100 to $200 \mathrm{~km}$ ), which do not include the processes and phenomena occurring on a subgrid scale (Wilby et al. 2004). Therefore, research on "compaction" and detailing of climate change information is necessary even to assess the threat posed by nature. This is especially important in case of complex topography regions, coastal or island locations, and in areas of highly heterogeneous land-cover. Two types of methods: dynamical and statistical downscaling are usefulness to solve the issue concerns transferring information from a large spatial scale represented by the lower resolution GCM to regional or local scale. Dynamical downscaling involves "nesting" of information from the global model in the regional model (RCM), which solves the equations of motion and the thermodynamic laws in a small spatial scale (10-50 km) (Mearns et al. 2003, Brzóska and Jaczewski 2011). Whereas, statistical downscaling (SD) refers to the identification of relation between small-scale variables (predictands) and large-scale variables (predictors) based on re- gression models (von Storch, 1995, 1999, Wilby et al. 2004, Miętus 1999). Both approaches play a significant role in evaluate of potential climate change impacts arising from future increases in greenhouse-gas concentrations. SD methodologies have a number of practical advantages over dynamical downscaling approaches especially in situations where low-cost, rapid assessments of local impact of climate change are required (Wilby and Dawson 2007).

The aim of the study was to (a) illustrate in map form temperature scenarios in Poland in the twenty-first century origin from global model (GCM) and dynamical downscaling model (RCM) (b) construct a statistical downscaling models (SDMs) and development of predictions of thermal conditions in Poland in twenty-first century, (c) compare the global model results with the statistical and dynamical models outcomes.

\section{Data and Methods}

In order to develop scenarios and to compare and evaluate the results from a global climate model and regional models for the Polish area in the twenty-first century at first verified availability of global simulation database. The next step 
concerns selection of one model from a number of GCMs from CMIP3 database (Coupled Model Intercomaprison Project 3) available through PCMDI servers (Program for Climate Model Diagnosis and Intercomparison). In the research author decided to select ECHAM5/MPI OM (Roeckner et al. 2006) originating from the Max Planck Institute for Meteorology (Germany). The choice of this model was caused by high quality in reconstructing of climate variability, which is confirmed by a number of studies (eg Kemball-Cook et al. 2002, Burkhardt and Becker 2006), and the availability of either monthly and daily temperature records in database. Moreover, comparison studies of most of GCMs (from CMIP3) which have been conducted by Macadam et al. 2010 and McMahon et al. 2015 prove the very good ECHAM5 performance. In the temperature ranking ECHAM5 was placed on third rank for Globe area and on second rank for Europe region. Selected records concern the control simulation called $20 \mathrm{C} 3 \mathrm{M}$ for the twentieth century (used to correct systematic errors in statistical models), and the scenario results for the twenty-first century showing the expected climate changes in the future. Scenario results based on dif- ferent level of GHG (greenhouse gases) emissions which are the products of very complex dynamical systems, determined by driving forces such as demographic development, socio-economic development, and technological change (Nakicenovic et al. 2000). In the studies A1B emission scenario was selected, among other equally probable highly uncertain emission pathways. A1B emission scenario assumes rapid economic growth, global population that peaks in mid-century and declines thereafter, and the rapid introduction of new and more efficient technologies and the use of sustainable energy sources (Nakicenovic et al. 2000). This assumptions establish stabilization experiment of carbon dioxide at the level of $720 \mathrm{ppm}$ at the end of the twenty-first century. Domain size of ECHAM5 (run 3 and run 4) A1B and ECHAM5 20C3M gridded data of $2 \mathrm{~m}$ above the ground air temperature was selected for central Europe limited with $0.0^{\circ}-30.0^{\circ}$ longitude and $45.0^{\circ}-60.0^{\circ}$ latitude. Horizontal resolution of chosen GCM is $1.9^{\circ} \times 1.9^{\circ}$ (about $180 \times 180 \mathrm{~km}$ ) (Fig. 2)

In the studies, results from RACMO2 model (Meijgaard et al. 2008) were used. The RCM was included in ENSEMBLES project which defined
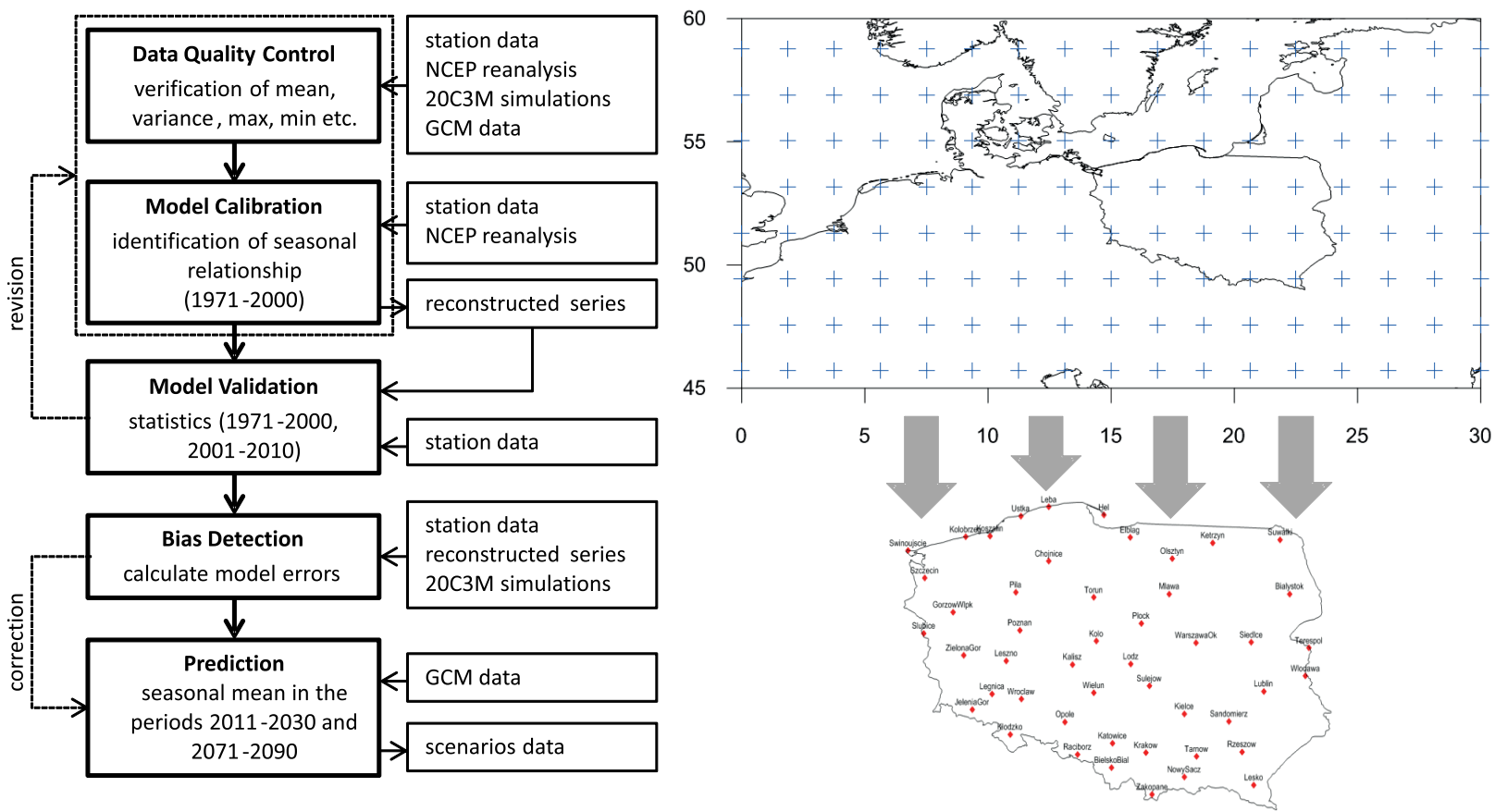

Fig. 2. Main stages in CCA method.

Left panel contains bolded boxes which represent main steps of the method. Data Quality Control was performed to verify basic statistics, histograms, outliers etc. Model Calibration phase identify connections between predictor and predictand. Model Validation check reliability of the model (with revision - back step if not reliable). Bias Detection based on reconstruction and original data was calculated to correct scenarios in XXI century. The final step Prediction concerns estimating seasonal means for two periods in XXI century. Horizontal vectors represent input/output data from/to right-side boxes. Right panel shows predictors spatial large-scale domain with grid horizontal resolution (blue crosses) and predictand small-scale field represented by measurement stations (red dots). 
future climate change within the European continent in the twenty-first century. RCM was nested in the ECHAM5 run 3 global simulation based on the A1B emission path, which is crucial to compare regional scenarios with selected global scenarios. The spatial domain of RCM gridded data (with horizontal resolution $50 \times 50 \mathrm{~km}$ ), was limited to the area of $13.0^{\circ}-25.0^{\circ}$ longitude and $48.0^{\circ}$ $-55.0^{\circ}$ latitude.

In the case of the second type of regional models namely statistical downscaling models (SDMs) author selected two methods based on linear relationships. The first one - CCA (Canonical Correlation Analysis) belongs to transfer function and the second one - WG (Weather Generator) related to the multiple regression.

The first phase of the modeling process using the CCA method was to control the quality and preparation of predictand input data i.e. the $2 \mathrm{~m}$ above the ground monthly mean air temperature of 48 stations irregularly localized in Poland originated from IMWM-NRI database (Institute of Meteorology and Water Management - National Research Institute). The predictor data concern monthly mean air temperature at the 0.995 sigma level (with the same resolution and spatial domain as GCM) derived from NCEP reanalysis (Kalnay et al. 1996). The time range of the two datasets concerned the period 1971-2010. CCA model is based primarily on identification of relationship between the predictand and the predictor. The predictor should be strongly connected with the predictand and the link must be time constant (time invariance). In the study author decided to create a model which is based on recognition the seasonal interrelation the air temperature measured at the Polish stations with estimated air temperature by NCEP reanalysis in the period 1971-2000 (Fig. 2). The first step of modeling is identification of the main variation patterns of predictand and predictor fields i.e. EOFs (Empirical Orthogonal Functions) (Miętus 1999, von Storch and Zwiers 2001, Miętus and Filipiak 2001, 2002, 2004, Wilks 2008). The second step concerns creating the combination of the predictand and predictor EOFs, which will identify the relationship between the two fields i.e. canonical maps. CCA method (Hotelling 1936, Barnett and Preisendorfer 1987, von Storch et al. 1993, Miętus 1999, von Storch and Zwiers 2001, Miętus and Filipiak 2001, 2002, 2004, Wilks
2008) is based on the maximization of the correlation between the predictand and predictor canonical time series. The result of modeling are pairs of canonical maps, where the first pair is the most correlated. Based on recognized relationships author reconstructed time series of historical air temperature. Reconstructed time series were separated into two periods: calibration period (1971-2000) and validation period (2001-2010), which is very important to evaluate temporally constancy requirement (Wilby et al. 2004). The verification process relied on comparing the historical and reconstructed series using statistical measures such as the $\mathrm{R}$ coefficient, the coefficient of determination $\left(R^{2}\right)$, Variance Ratio, Root Mean Square Error (RMSE), Mean Absolute Error (MAE), Mean Bias, differences of trends. The $\mathrm{R}$ coefficient is Pearson correlation. The coefficient of determination represents the magnitude of explained variance by model. The Variance Ratio denoting the ratio of the reconstructed variance to the observational variance. The Mean Bias is an absolute difference between observational and reconstructed averages. The RMSE and the MAE measure the average magnitude of the errors without considering their direction. These both validation scores can be used together to diagnose the variation in the errors in a dataset of predictions. The RMSE will always be larger or equal to the MAE. The greater difference between them means the greater values in the individual errors in the sample. If the RMSE is equal to MAE, then all the errors are of the same magnitude. Both the MAE and the RMSE can range from 0 to $\infty$. They are negatively-oriented scores: lower values are better.

The occurrence of insignificant differences of above statistics between the calibration and validation periods allow to assess that the model is representative, i.e. fulfills the basic assumption namely statistical temporally constancy of identified downscaling connections. Satisfied the requirements of high-quality reconstruction, time invariance and corrections of systematic errors allow to develop scenarios of climate change applying data from the GCM.

Modeling procedure for WG method is similar to canonical analysis i.e. identification a linear connections of air temperature on stations and air temperature originated from reanalysis. The main difference is that the linkage was detected, 

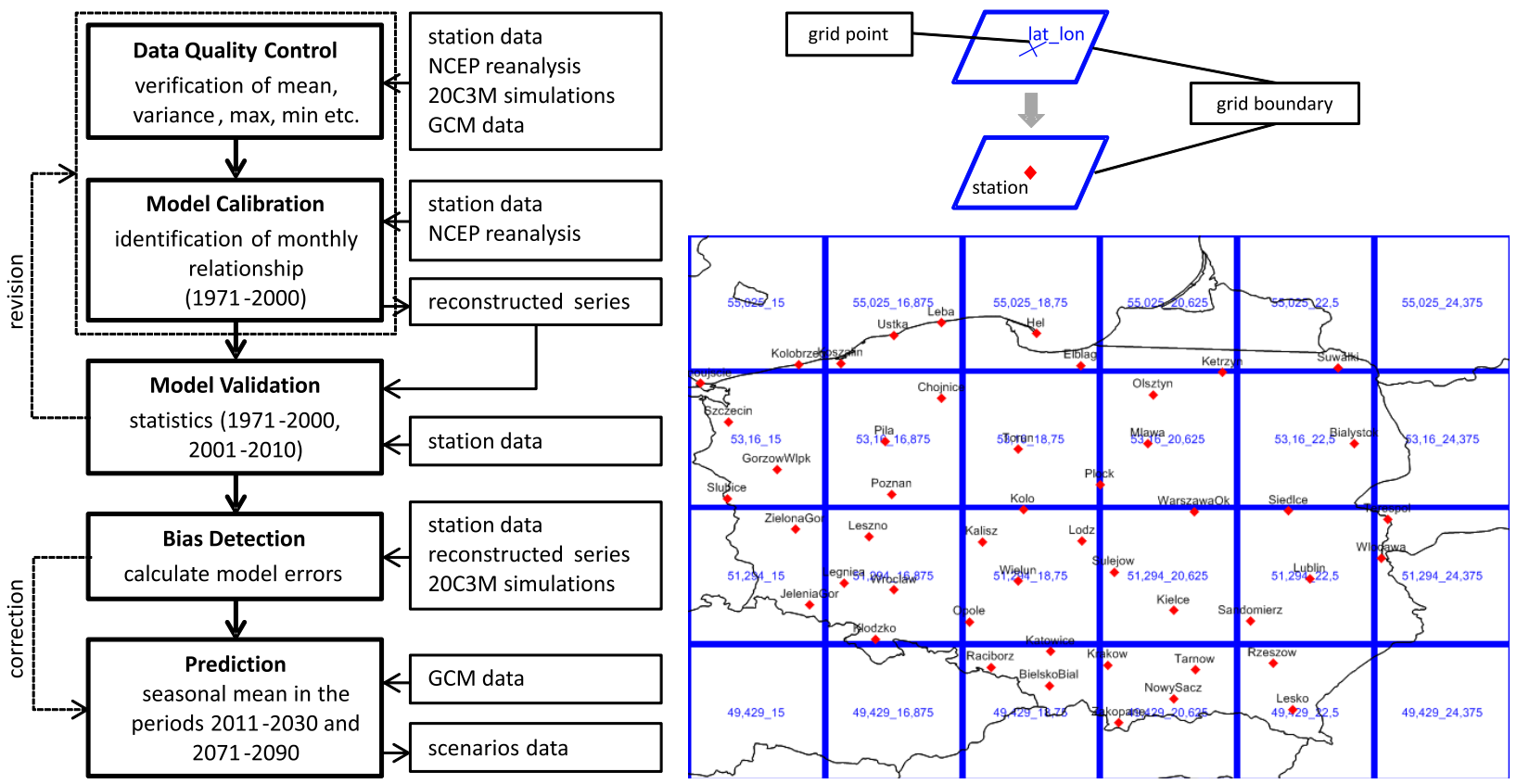

Fig. 3. Main stages in WG method.

Left panel contains bolded boxes which represent main steps of the method. Data Quality Control was performed to verify basic statistics, outliers etc. Model Calibration phase identify connections between predictor and predictand. Model Validation check reliability of the model (with revision - back step if not reliable). Bias Detection based on reconstruction and original data was calculated to correct scenarios in XXI century. The final step Prediction concerns estimating seasonal means for two periods in XXI century. Horizontal vectors represent input/ output data from/to right-side boxes. Right panel shows predictors large-scale domain with grid boxes (blue square) and predictand smallscale field represented by measurement stations (red dots).

in monthly scale using daily data, between grid data and individual station data which localized within the grid boundary (Fig. 3). WG model generates a time series of meteorological records for a specific point, based on multiple regression. Reconstructed time series characterized by the same statistical parameters (mean, variance) as an observational series but do not replicate observed sequences "day to day" (Wilks and Wilby, 1999). In order to validate the model, the reconstructed series were compared with the historical values using the same statistics such as CCA method. If requirements of high quality of reconstructing and temporally constancy were fulfilled and mean biases were corrected the prediction of changes in thermal conditions in Poland in the twenty-first century could be developed. Daily air temperature prediction was aggregated to monthly values for comparison analysis with the GCM and RCM results.

The final stage of the study was to develop a prediction of the main results of global and regional models in the maps form of seasonal mean air temperature in the periods 2011-2030 and 2071-2090 in Poland in relation to the reference period 1971-2000.

\section{Results}

\section{Validation of statistical models}

Validation of statistical downscaling technique were based on a comparison of the observational and reconstructed series using a variety of statistical measures in order to assess the models quality and accuracy. Interpretation of verification results for CCA and WG models cannot be comparable, mainly due to the different time step of the input data. CCA model input data concerns monthly records which was calibrated in seasonal scale, for example for winter, three months December, January, February (DJF) in the 30-year period which equates to 90 records. Whereas WG model was fed daily data and calibrated in monthly scale and then results were aggregated to the seasonal scale, for example for winter, number of days in three months (DJF) are 90 in the 30-year period, which equates to 2,700 records. Therefore, author did not compare validation statistics of both models. Even worse validation results of the WG model than the CCA model is not evidence of poor quality weather generator reconstruction. 
Table 1. Verification statistics of WG and CCA models developed for the mean air temperature of Poland (average of all stations) in several seasons (DJF, MAM, JJA, SON) in the calibration period 1971-2000.

\begin{tabular}{|c|c|c|c|c|c|c|c|}
\hline Season & Statistics & Measurment & CCA & Modeled & Measurment & WG & Modeled \\
\hline \multirow{8}{*}{ DJF } & $\mathrm{R}$ & & 0.98 & & & 0.92 & \\
\hline & Expl. Variance & & 0.96 & & & 0.85 & \\
\hline & Variance Ratio & & 0.96 & & & 0.72 & \\
\hline & $\operatorname{MAE}\left({ }^{\circ} \mathrm{C}\right)$ & & 0.47 & & & 1.56 & \\
\hline & RMSE $\left({ }^{\circ} \mathrm{C}\right)$ & & 0.59 & & & 1.69 & \\
\hline & Mean $\left({ }^{\circ} \mathrm{C}\right)$ & -0.88 & & -0.84 & -0.88 & & -0.62 \\
\hline & Mean Bias $\left({ }^{\circ} \mathrm{C}\right)$ & & 0.04 & & & 0.26 & \\
\hline & Trend $\left({ }^{\circ} \mathrm{C} / 30 \mathrm{yr}\right)$ & 0.91 & & 0.86 & 0.22 & & 0.10 \\
\hline \multirow{8}{*}{ MAM } & $\mathrm{R}$ & & 0.99 & & & 0.92 & \\
\hline & Expl. Variance & & 0.98 & & & 0.85 & \\
\hline & Variance Ratio & & 0.99 & & & 0.79 & \\
\hline & $\operatorname{MAE}\left({ }^{\circ} \mathrm{C}\right)$ & & 0.40 & & & 1.77 & \\
\hline & $\operatorname{RMSE}\left({ }^{\circ} \mathrm{C}\right)$ & & 0.50 & & & 1.95 & \\
\hline & Mean $\left({ }^{\circ} \mathrm{C}\right)$ & 7.62 & & 7.68 & 7.62 & & 7.11 \\
\hline & Mean Bias $\left({ }^{\circ} \mathrm{C}\right)$ & & 0.06 & & & -0.51 & \\
\hline & Trend $\left({ }^{\circ} \mathrm{C} / 30 \mathrm{yr}\right)$ & 1.73 & & 1.41 & 0.34 & & 0.20 \\
\hline \multirow{8}{*}{ JJA } & $\mathrm{R}$ & & 0.97 & & & 0.86 & \\
\hline & Expl. Variance & & 0.94 & & & 0.74 & \\
\hline & Variance Ratio & & 0.93 & & & 0.57 & \\
\hline & $\operatorname{MAE}\left({ }^{\circ} \mathrm{C}\right)$ & & 0.32 & & & 1.23 & \\
\hline & RMSE $\left({ }^{\circ} \mathrm{C}\right)$ & & 0.39 & & & 1.38 & \\
\hline & Mean $\left({ }^{\circ} \mathrm{C}\right)$ & 16.81 & & 16.87 & 16.81 & & 16.36 \\
\hline & Mean Bias $\left({ }^{\circ} \mathrm{C}\right)$ & & 0.06 & & & -0.45 & \\
\hline & Trend $\left({ }^{\circ} \mathrm{C} / 30 \mathrm{yr}\right)$ & 1.09 & & 1.31 & 0.25 & & 0.25 \\
\hline \multirow{8}{*}{ SON } & $\mathrm{R}$ & & 0.99 & & & 0.91 & \\
\hline & Expl. Variance & & 0.98 & & & 0.83 & \\
\hline & Variance Ratio & & 0.96 & & & 0.78 & \\
\hline & $\operatorname{MAE}\left({ }^{\circ} \mathrm{C}\right)$ & & 0.38 & & & 1.92 & \\
\hline & RMSE $\left({ }^{\circ} \mathrm{C}\right)$ & & 0.45 & & & 2.05 & \\
\hline & Mean $\left({ }^{\circ} \mathrm{C}\right)$ & 8.09 & & 8.23 & 8.09 & & 7.63 \\
\hline & Mean Bias $\left({ }^{\circ} \mathrm{C}\right)$ & & 0.14 & & & -0.46 & \\
\hline & Trend $\left({ }^{\circ} \mathrm{C} / 30 \mathrm{yr}\right)$ & 0.07 & & 0.10 & 0.10 & & 0.06 \\
\hline
\end{tabular}

In the winter season in Poland (1971-2000) the $\mathrm{R}$ coefficient for both models is high, for CCA model equals 0.98 and for WG model reaches 0.92 (Table 1). In the case of CCA model, Variance Ratio (indicating the ratio of the reconstructed and observational variances), is the same as the coefficient of determination, i.e. 0.96. However, this statistic for WG method reaches 0.72 which means a significant underestimation of the modeled variance. The calculated MAE and RMSE statistics for the model CCA are approximately $0.50^{\circ} \mathrm{C}$, and for model WG about $1.60^{\circ} \mathrm{C}$. Mean air temperature in Poland provided by CCA model in the calibration period is essentially the same as the observed mean value. Whereas, multi-year mean temperature of WG model is higher of about $0.25^{\circ} \mathrm{C}$. However, the Mean Bias reaches the lowest value on the seasonal background. The trend in Poland for monthly data are practically identical and reached approximately $0.90^{\circ} \mathrm{C} / 30$ years. There is also a slight difference in the case of the daily data, which the trend is low, not exceeding $0.20^{\circ} \mathrm{C} / 30$ years.

Spring season in Poland is also characterized by the high correlation coefficients on a monthly and daily scale, reach respectively 0.99 and 0.92 (Table 1). Variance Ratios for both models are similar to winter values. RMSE and MAE for CCA equal to $0.40^{\circ} \mathrm{C}$ and $0.50^{\circ} \mathrm{C}$ relatively, for WG model are $1.77^{\circ} \mathrm{C}$ and $1.95^{\circ} \mathrm{C}$ relatively. In the case of WG method in relation to the other seasons the greatest difference between RMSE and corresponding MAE value means that model make many individual large errors. The mean 
air temperature in the period $1971-2000$ by CCA model is almost identical as compared to the observed values. However, the average value reconstructed by the WG model is lower by about $0.50^{\circ} \mathrm{C}$. In the WG method the Mean Bias corrections in spring season are the highest among all seasons. Both statistical models underestimated the trend of about $0.30^{\circ} \mathrm{C} / 30$ years for CCA and almost $0.15^{\circ} \mathrm{C} / 30$ years for WG.

In the summer, the $\mathrm{R}$ coefficient is high only for the CCA model i.e. 0.97 (Table 1). Reconstructed series by WG model is poor correlated and reach 0.86. Also Variance Ratio is the lowest and not exceed 0.60 , which indicates that only near a half variance was reconstructed in relation to observational variance. However, the RMSE and MAE in both models are the lowest of all the seasons and the CCA assumes the value $0.32^{\circ} \mathrm{C}$ and $0.39^{\circ} \mathrm{C}$ relatively, WG characterized by $1.23^{\circ} \mathrm{C}$ and $1.38^{\circ} \mathrm{C}$ relatively. The mean air temperature reconstructed by CCA model is slightly overestimated, while the WG model significantly underestimates mean value of about $0.50^{\circ} \mathrm{C}$. Reconstruction of the trend in the WG model is perfect, but according to the CCA model trend is slightly overestimated (by about $0.20^{\circ} \mathrm{C} / 30$ years).

In the autumn season, both models indicate a high R coefficient of 0.99 (CCA) and 0.91 (WG) (Table 1). Variance Ratios for both models are similar in relation to corresponding spring season. RMSE and MAE of the CCA model also are comparable to the spring values. However, for WG model MAE and RMSE assumes the highest values and peaked respectively over $1,90^{\circ} \mathrm{C}$ and $2.00^{\circ} \mathrm{C}$, what indicate on the poor accuracy of reconstructed series. The Mean Bias in the case of CCA method is the highest, near $0.15^{\circ} \mathrm{C}$ and for WG model the value is similar to summer season. In the autumn, for monthly and daily data the trend is relatively low compared to other seasons and amounts to $0.10^{\circ} \mathrm{C} / 30$ years.

The calculated correlation coefficient in the validation period 2001-2010 in each season are similar to the values of the calibration period, which proves the stability of the predictor - predictand relationship.

Another validation measure is the $\mathrm{Q}-\mathrm{Q}$ plot (Quantile-Quantile plot). This chart compares two probability distributions (measurements and modeled) by plotting their quantiles against each other on XY plot. If the two compared dis- tributions are similar, the points in the Q-Q plot will approximately lie on the line $y=x$. Quantile values located above the line $\mathrm{y}=\mathrm{x}$ indicate overestimation of the statistical model, and a values below the line means underestimation (Fig. 4). Q-Q plot is generally a more powerful approach than the common technique of comparing histograms, but it is more complicated in interpretation. For example if the main trend of the Q-Q plot is flatter than the line $y=x$, the measurement distribution is more dispersed than the modeled distribution. Conversely, if the main trend of the $\mathrm{Q}-\mathrm{Q}$ plot is steeper than the line $\mathrm{y}=\mathrm{x}$, the measurement values is more concentrated around average than the modeled values. Q-Q plots are often arced, or " $\mathrm{S}$ " shaped, indicating that one of the distributions is more skewed than the other, or that one of the distributions has longer tails than the other (Wilks 2011).

Model CCA data distribution characterized by a high compatibility to the empirical distribution at any season of the year (Fig. 4). This model overestimates low quantile value in winter and autumn. Extremely high values are slightly underestimated in summer and autumn. However, WG model is only best fitted around of the median value in winter and summer. In the case of other seasons (MAM, SON) the best fit exists around the first quartile. In each time of year, the WG model overestimates low values, while high values are underestimated. The fitted line is flatter which proves the higher dispersion in observational data than modeled data especially in summer case (confirmed by the lowest Variance Ratio).

\section{Scenarios}

Scenarios of thermal conditions changes in the twenty-first century in Poland developed based on two runs: 3 and 4 . The selection was dictated by the availability of research material on the database servers concerning GCM and RCM data.

In the period 2011-2030 the highest results differences between the two runs are in the winter season (Fig. 5). Run 3 shows much lower anomalies not exceeding $0.5^{\circ} \mathrm{C}$ in relation to the period 1971-2000. According to the run 4 increase is higher and assume the values from $1.8^{\circ} \mathrm{C}$ in the northern Poland (ECHAM5) to even $2.2^{\circ} \mathrm{C}$ in the north-east of the country (CCA). 

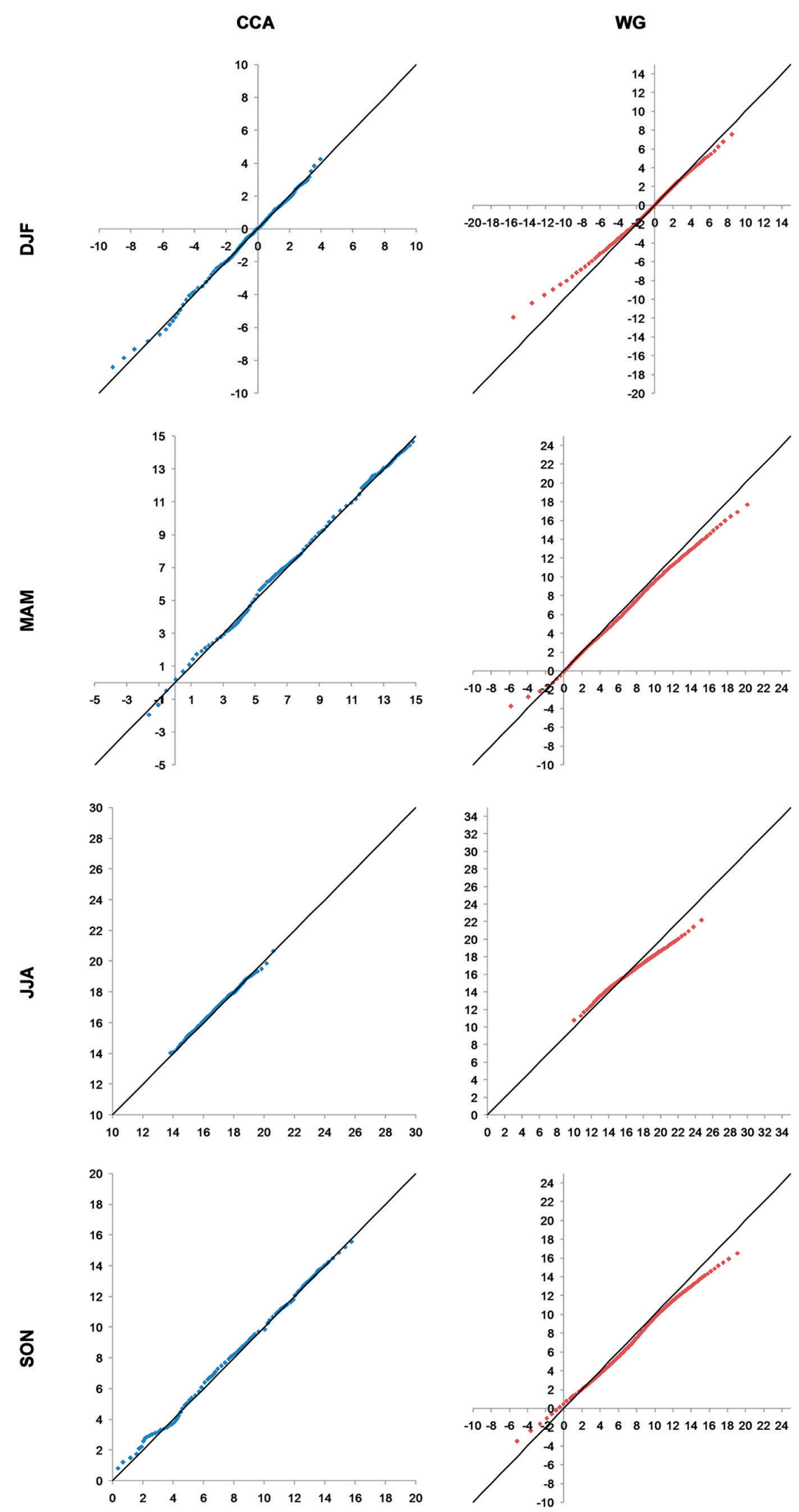

Fig. 4. Q-Q plot of the mean air temperature $\left({ }^{\circ} \mathrm{C}\right)$ in several seasons (DJF - winter, MAM - spring, JJA - summer, SON - autumn) by CCA and WG models in Poland in the period 1971-2000 (x-axis - measured values, y-axis - modeled values). 

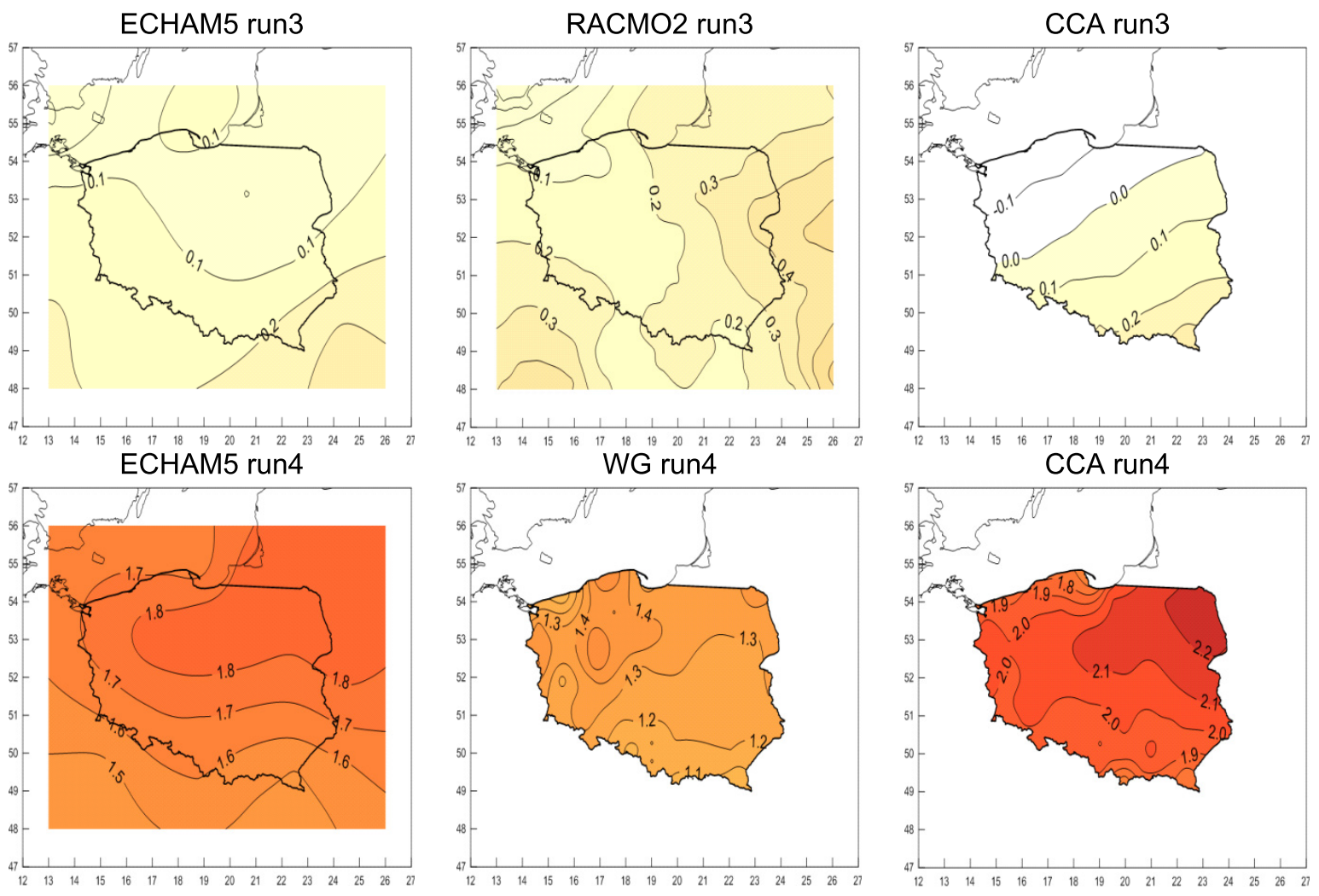

Fig. 5. Anomalies of air temperature $\left({ }^{\circ} \mathrm{C}\right)$ in the winter season (DJF) 2011-2030 in relation to reference period (1971-2000) in Poland based on A1B emission scenario for models: ECHAM5 run 3and 4, RACMO2 run 3, CCA run 3 and 4, WG run 4.
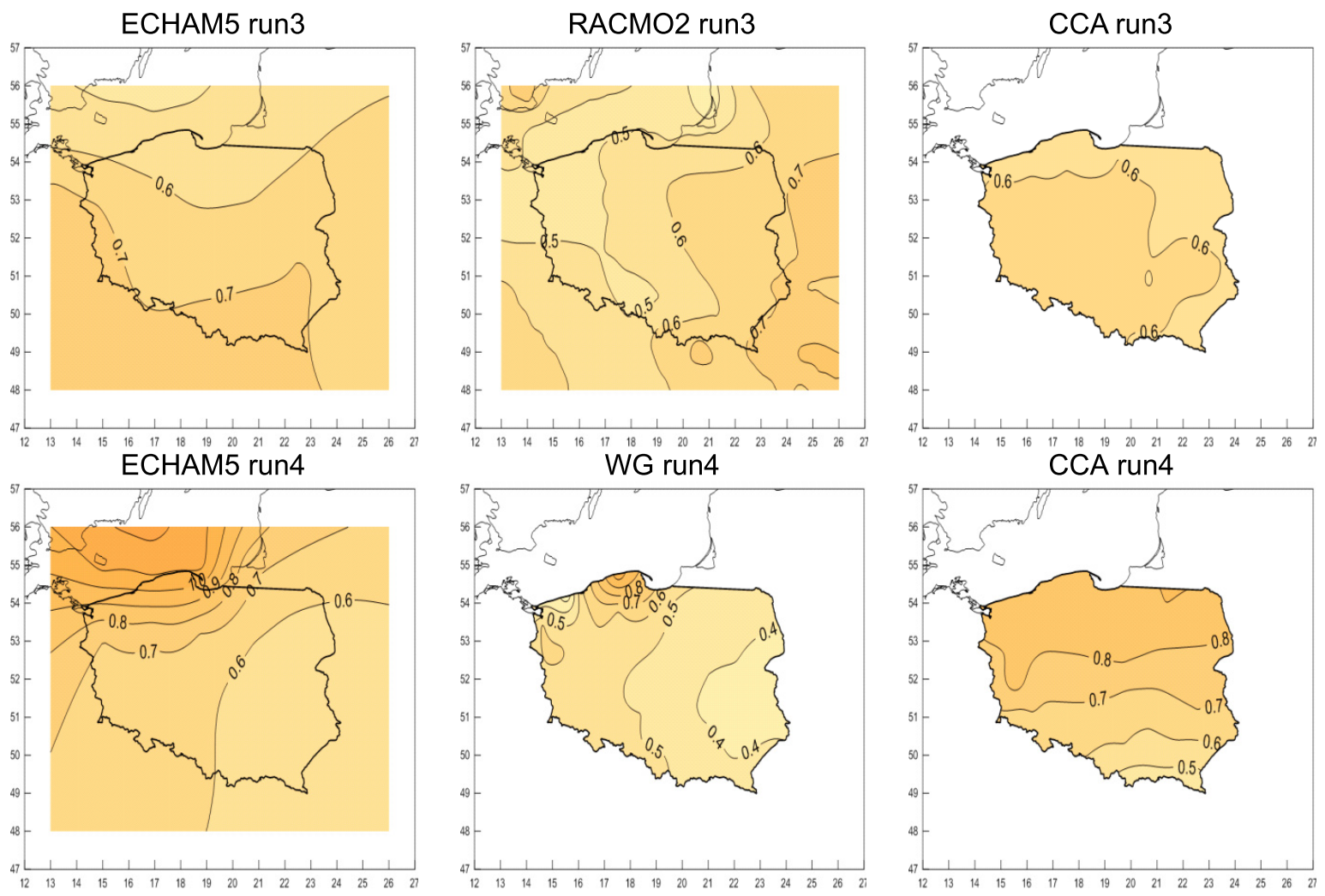

Fig. 6. Anomalies of air temperature $\left({ }^{\circ} \mathrm{C}\right)$ in the spring season (MAM) 2011-2030 in relation to reference period (1971-2000) in Poland based on A1B emission scenario for models: ECHAM5 run 3and 4, RACMO2 run 3, CCA run 3 and 4, WG run 4. 
In the spring season (2011-2030) the range of the anomalies of two runs is similar, but the spatial variability is different (Fig. 6). For dynamical models run 3 represents an increase of values from north to south, from about $0.5^{\circ} \mathrm{C}$ to $0.7^{\circ} \mathrm{C}$. Whilst, CCA model results indicates almost equal increase of about $0.6^{\circ} \mathrm{C}$ at whole area. Results based on run 4 for all three models ECHAM5, WG and CCA show as the highest temperature in the north of the country account above $0.8^{\circ} \mathrm{C}$, even exceeding $1.0^{\circ} \mathrm{C}$ on the eastern coast (ECHAM5 and WG).

Expected temperature anomalies in the summer season in the period $2011-2030$ by run 3 account $0.5-1.0^{\circ} \mathrm{C}$ (Fig. 7). The highest increase presents CCA model in the mid-west of the country. Results of run 4 simulation characterized by higher anomalies especially in the north-west Poland, ranging from $1.4^{\circ} \mathrm{C}$ (ECHAM5 and WG) to $1.7^{\circ} \mathrm{C}$ (CCA).

In the autumn season (2011-2030) run 3 results indicate a temperature growth of $0.7^{\circ} \mathrm{C}$ in the north-west of the country to $0.9^{\circ} \mathrm{C}$ the south-east (Fig. 8). In the case of run 4 results of ECHAM5 and CCA models represent similar temperature increase from west to east Poland (from 1.6 to $2.0^{\circ} \mathrm{C}$ ). Model WG generally shows a positive anomalies in Poland of approximately $1.5^{\circ} \mathrm{C}$.

Scenarios of thermal condition changes in Poland at the end of the century (2071-2090) are characterized by very high increase in all seasons by each run. In winter, the results based on the run 3 indicate explicitly the highest increase of temperature in the eastern Poland from near to $4.0^{\circ} \mathrm{C}$ by $\mathrm{RACMO} 2$ to almost $5.0^{\circ} \mathrm{C}$ by CCA (Fig. $9)$. However, in the case of the run 4 the highest increase was provided by CCA model reaches more than $5.5^{\circ} \mathrm{C}$ in the north - eastern part of the country. Global model in this part of the Poland shows lower increase of approximately $4.8^{\circ} \mathrm{C}$, and the model WG less than $4.0^{\circ} \mathrm{C}$. Probably the lowest increase by runs 3 and 4 will occur on the coast with the lowest values of about $2.5^{\circ} \mathrm{C}$ (WG model).

In the spring season results from run 3 indicate on temperature increase from south-west to northern Poland (Fig. 10). The highest anomalies above $3.0^{\circ} \mathrm{C}$ probably occur in the north-west part (CCA model). Actually, results of CCA for run 4 are similar, the highest temperature growth is expected in north-east area of about $3.4^{\circ} \mathrm{C}$. ECHAM5 and WG models concern lower anom- alies in the central part of Poland reach below $3.0^{\circ} \mathrm{C}$ and higher values on the coast and mountainous regions of about $3.0^{\circ} \mathrm{C}$.

Probably changes of temperature in the summer in the period 2071-2090 will be characterized by high gradient in both runs especially in results of statistical models (Fig. 11). Run 3 presents fast anomalies rise from north to south Poland, ranging from about $2.5^{\circ} \mathrm{C}$ (ECHAM5, RACMO2) to about $3.0^{\circ} \mathrm{C}$ (ECHAM5) or $4.0^{\circ} \mathrm{C}$ (RACMO2). CCA model indicates on the highest anomalies in the central of the country amount $4.0-4,5^{\circ} \mathrm{C}$ (Fig. 5). In the case of run 4, ECHAM5 and CCA maps show similar spatial distribution of anomalies as corresponding run 3 results. However values are slightly higher of about $0.5-1.0^{\circ} \mathrm{C}$. WG model indicate on lower anomalies at the whole country reach above $3.0^{\circ} \mathrm{C}$ with maximum values in the central part of about $4.0^{\circ} \mathrm{C}$.

All results in autumn presents the same pattern for run 3 and 4, namely the higher anomalies occur on the south-east Poland and the lower values occur on the north-west (Fig. 12). However, only ECHAM5 and CCA models results indicate values above $4.0^{\circ} \mathrm{C}$. In the other hand $\mathrm{RACMO} 2$ and WG models presents the lowest values below $2.5^{\circ} \mathrm{C}$.

\section{Summary and Conclusions}

Achieved satisfactory results of the statistical models verification confirmed the usefulness of the downscaling method to create prediction of climate change. Statistical downscaling method, supported by the results of RCM, is a more appropriate technique to detailed information of global simulations than used simple interpolation of GCM results to the required resolution (sometimes called "unintelligent downscaling"). Simple spatial interpolation does not allow for the detection of local aspects of climate change, which downscaling models included.

The main results of the paper often indicated on large differences in the detection of local aspects of seasonal temperature changes in Poland depending on the various downscaling method. Furthermore, the individual simulations provided by two selected GCM runs characterized by miscellaneous results. Therefore, author expects significant differences in the scenarios provided 

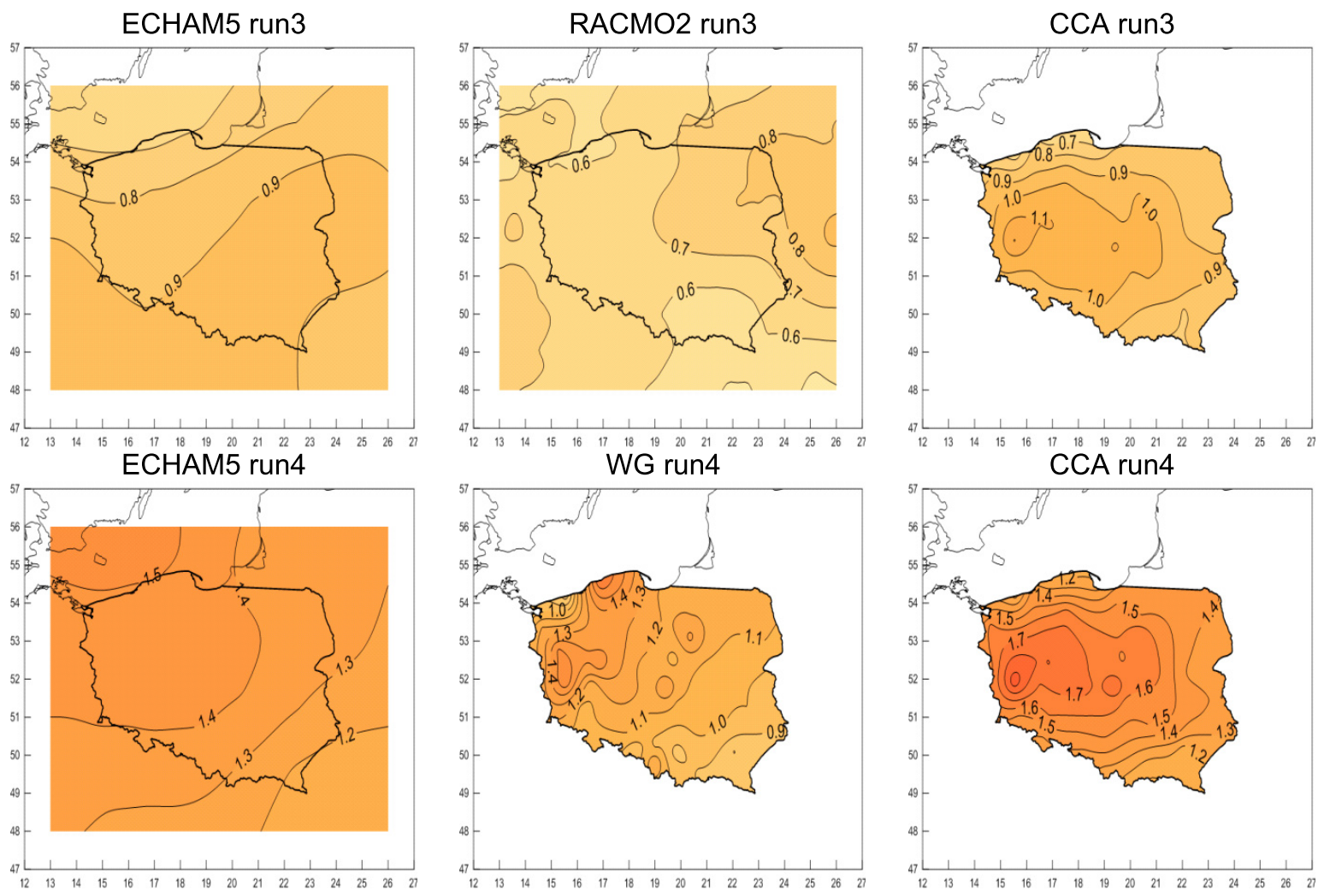

Fig. 7. Anomalies of air temperature $\left({ }^{\circ} \mathrm{C}\right)$ in the summer season (JJA) 2011-2030 in relation to reference period (1971-2000) in Poland based on A1B emission scenario for models: ECHAM5 run 3and 4, RACMO2 run 3, CCA run 3 and 4, WG run 4.
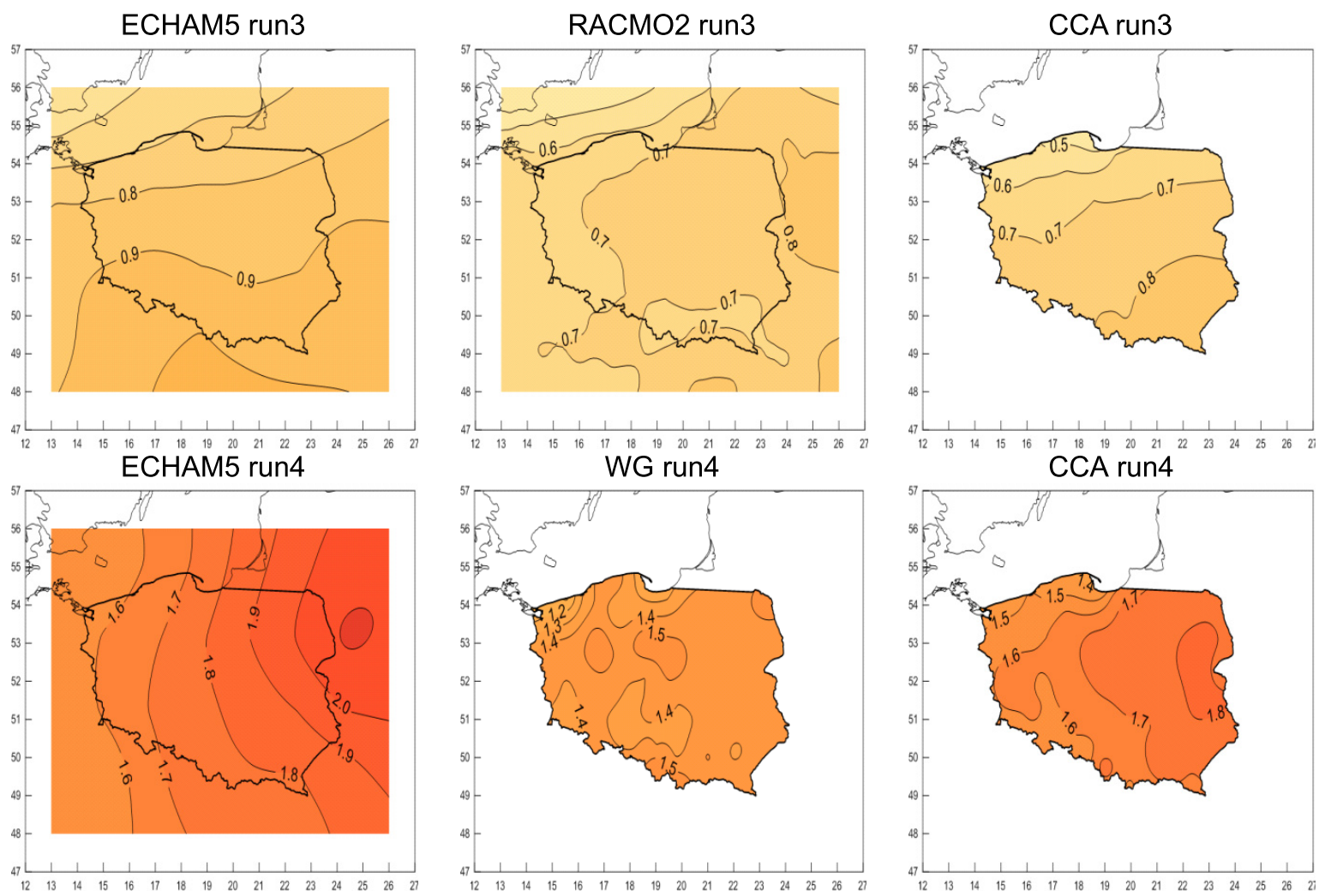

Fig. 8. Anomalies of air temperature $\left({ }^{\circ} \mathrm{C}\right)$ in the autumn season (SON) 2011-2030 in relation to reference period (1971-2000) in Poland based on A1B emission scenario for models: ECHAM5 run 3and 4, RACMO2 run 3, CCA run 3 and 4, WG run 4. 

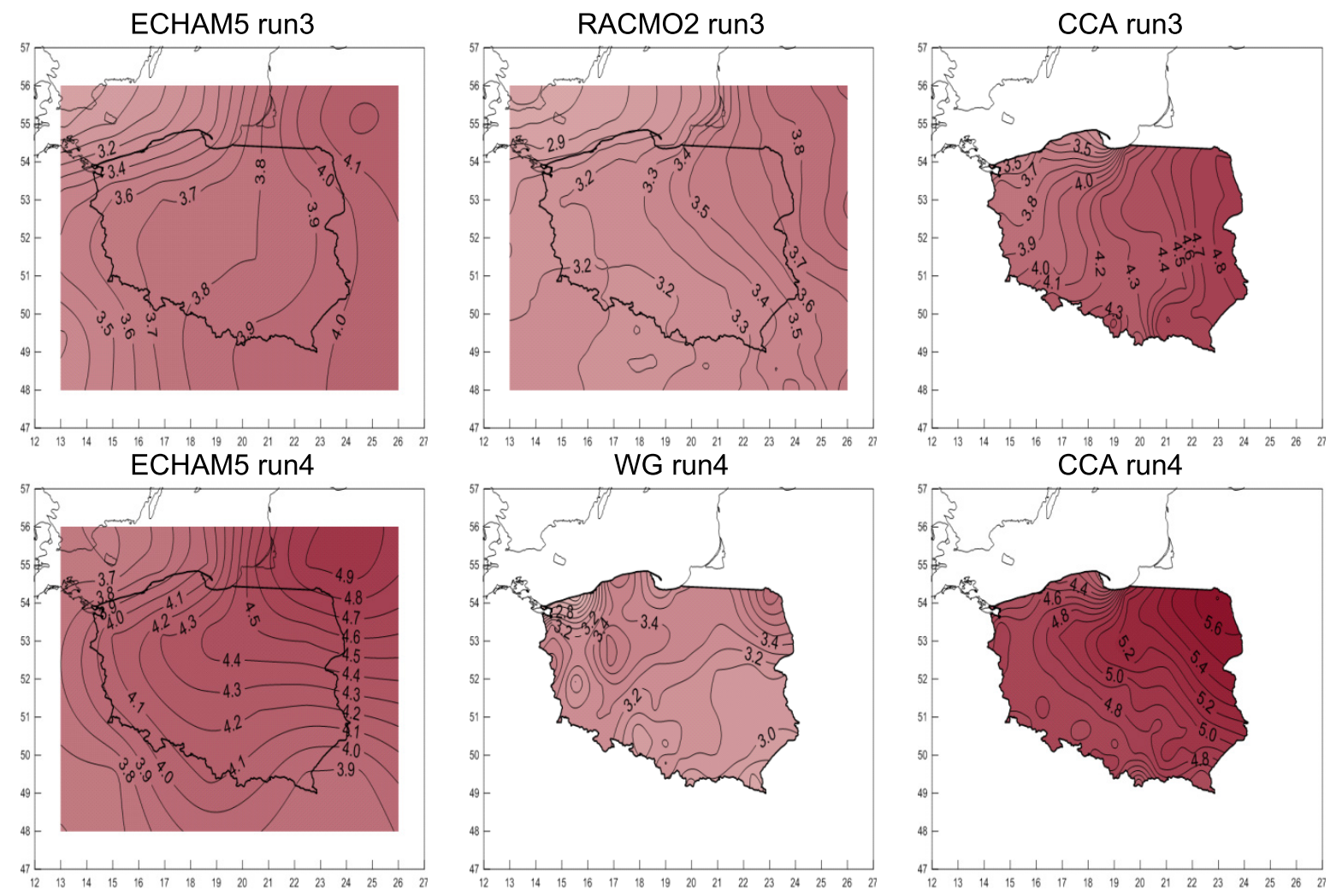

Fig. 9. Anomalies of air temperature $\left({ }^{\circ} \mathrm{C}\right)$ in the winter season (DJF) 2071-2090 in relation to reference period (1971-2000) in Poland based on A1B emission scenario for models: ECHAM5 run 3and 4, RACMO2 run 3, CCA run 3 and 4, WG run 4.
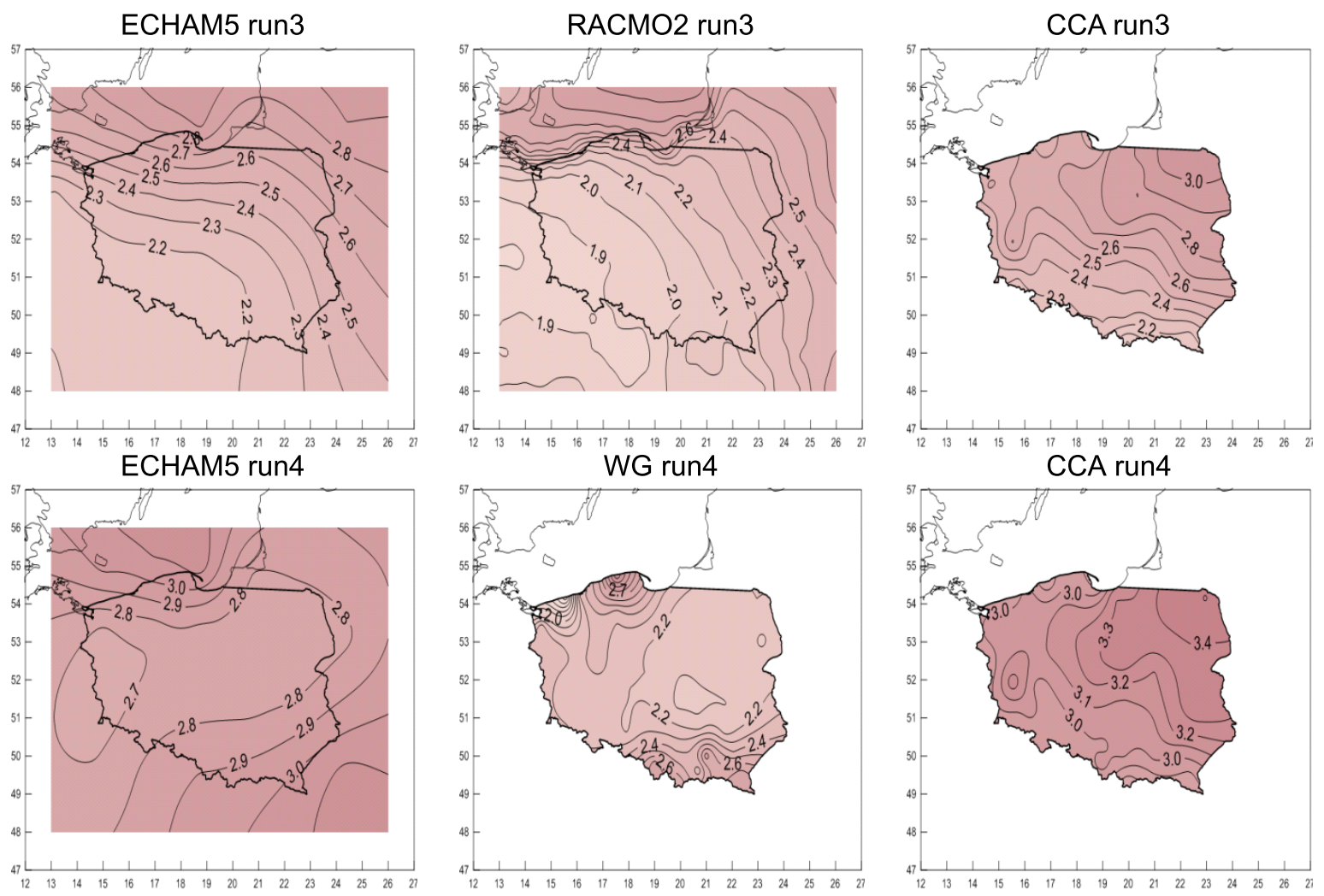

Fig. 10. Anomalies of air temperature $\left({ }^{\circ} \mathrm{C}\right)$ in the spring season (MAM) 2071-2090 in relation to reference period (1971-2000) in Poland based on A1B emission scenario for models: ECHAM5 run 3and 4, RACMO2 run 3, CCA run 3 and 4, WG run 4. 

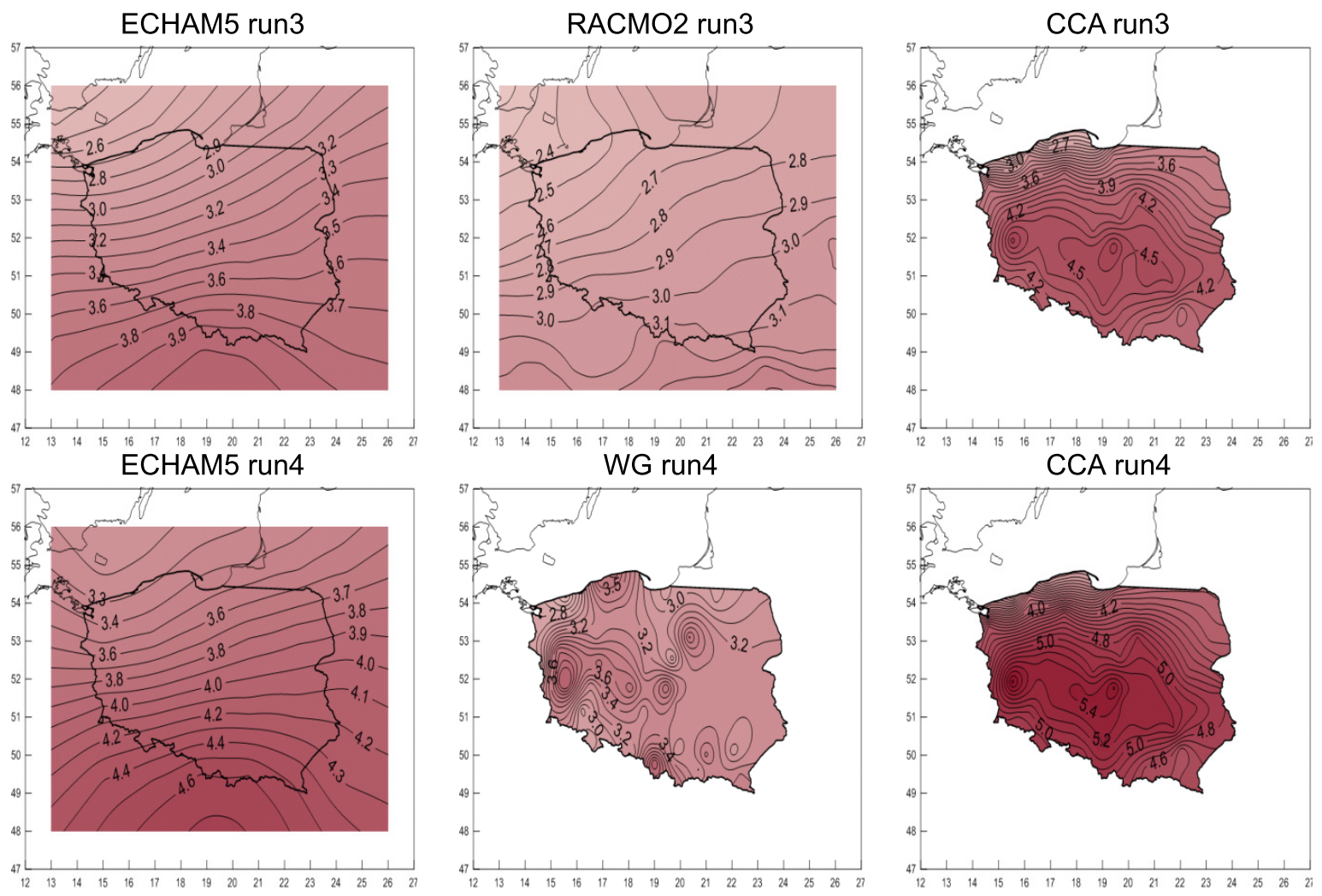

Fig. 11. Anomalies of air temperature $\left({ }^{\circ} \mathrm{C}\right)$ in the summer season (JJA) 2071-2090 in relation to reference period (1971-2000) in Poland based on A1B emission scenario for models: ECHAM5 run 3and 4, RACMO2 run 3, CCA run 3 and 4, WG run 4.
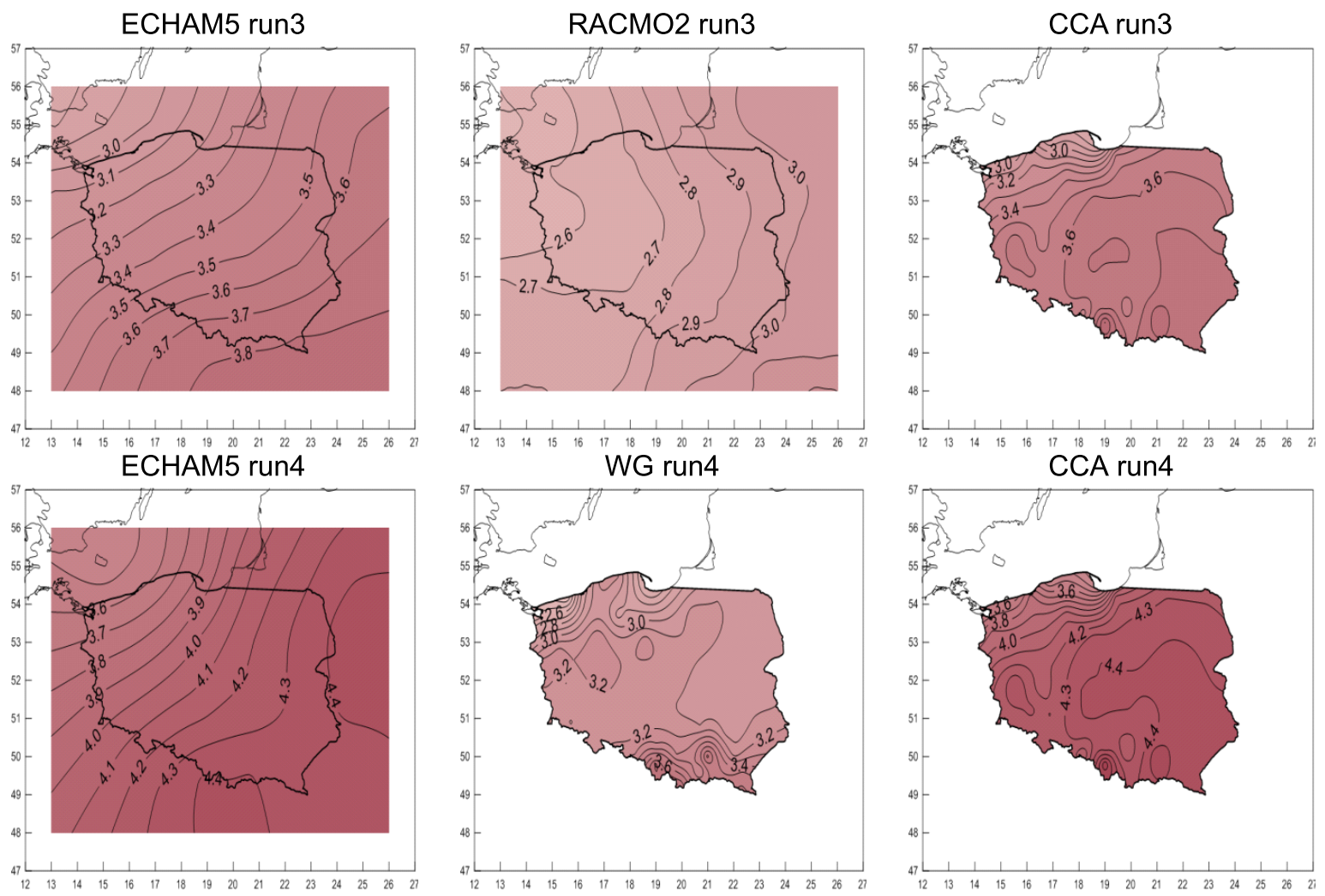

Fig. 12. Anomalies of air temperature $\left({ }^{\circ} \mathrm{C}\right)$ in the autumn season (SON) 2071-2090 in relation to reference period (1971-2000) in Poland based on A1B emission scenario for models: ECHAM5 run 3and 4, RACMO2 run 3, CCA run 3 and 4, WG run 4. 
by downscaling models calibrated on the other global simulations from other GCMs. These differences suggest an occurrence of uncertainty range of the temperature scenarios. To identify and assess of the uncertainty range it is necessary to make an ensemble. Ensemble is the average of the different experiments with the maximum and minimum values indicating the uncertainty range. Additionally, the ensemble should be developed separately for each of the equally probable emission scenarios which assume different development of the world civilization. Above procedure would fully determine the scope of the uncertainty and evaluate the risks of hazards connected with climate change. Therefore, further research focused on greater number of various regional simulations is necessary in terms of mitigation and adaptation to climate change.

\section{Acknowledgements}

The papers presents the outcomes of the research carried out as a part of University of Gdansk research project contributing to the development of young scientists and $\mathrm{PhD}$ students. Project title: Scenarios of future changes in the thermal conditions in Poland in the twenty-first century regional models on the global models background no. 538-G140-1190-12.

\section{References}

Barnett T.P., Preisendorfer R., 1987. Origins and levels of monthly and seasonal forecast skill for United States surface air temperature determined by canonical correlation analysis. Mon. Wea. Rev. 115: 1825-1850.

Brzóska B., Jaczewski A., 2011. Nearby twenty years in the light of the results of the regional modeling based on selected thermal indicators. Acta Geographica Silesiana 1. WNoZ UŚ-ZPKWŚ, Sosnowiec-Będzin: 17-21 (in Polish).

Burkhardt U., Becker E., 2006. A Consistent Diffusion-Dissipation in the ECHAM Climate Model. Monthly Weather Review 134, 4: 1194-1204.

Hotelling H., 1936. Relations between two sets of variants. Biometrika 28: 321-377.

IPCC, 2007. Climate Change 2007: Synthesis Report. Contribution of Working Groups I, II and III to the Fourth Assessment Report of the Intergovernmental Panel on Climate Change. IPCC, Geneva, Switzerland.

Kalnay E., Kanamitsu M., Kistler R., Collins W., Deaven D., Gandin L., Iredell M., Saha S., White G., Woollen J., Zhu Y., Leetmaa A., Reynolds R., 1996. The NCEP/NCAR 40year Reanalysis Project. Bulletin of the American Meteorological Society 77: 437-471.
Kemball-Cook S., Wang B., Xiouhua F., 2002. Simulation of the Intraseasonal Oscillation in the ECHAM-4 Model: The Impact of Coupling with an Ocean Model. Journal of the Atmospheric Sciences 59, 9: 1433-1453.

Macadam I., Pitman A.J., Whetton P.H., Abramowitz G., 2010. Ranking climate models by performance using actual values and anomalies: Implications for climate change impact assessments. Geophys. Res. Lett. 37, L16704. DOI: 10.1029/2010GL043877.

McMahon T.A., Peel M.C., Karoly D.J., 2015. Assessment of precipitation and temperature data from CMIP3 global climate models for hydrologic simulation. Hydrol. Earth Syst. Sci. 19: 361-377. DOI: 10.5194/hess-19-361-2015: 362-377.

Mearns L.O., Giorgi F., Whetton P., Pabon D., Hulme M., Lal M., 2003. Guidelines for Use of Climate Scenarios Developed from Regional Climate Model Experiments by DDC of IPCC TGCIA Final Version - 10/30/03.

Meijgaard E., Ulft L.H., Berg W.J., Bosveld F.C., Hurk B.J. J.M., Lenderink G., Siebesma A.P., 2008. The KNMI regional atmospheric climate model RACMO version 2.1. Technical report; TR-302.

Miętus M., 1999. The role of regional atmospheric circulation in creating climatic and oceanographic conditions along Polish coastal zone. Research Materials of IMGW, Series: Meteorology 29: 1-157 (in Polish).

Miętus M., Filipiak J., 2001. Structure of temporal-spatial variability of thermal conditions in the Gdansk Gulf region. Research Materials of IMGW, Series: Meteorology 32: 1-53 (in Polish).

Miętus M., Filipiak J., 2002. Impact of North Atlantic SST on large scale atmospheric circulation and thermal conditions in Poland in XXI century in the Euro-Atlantic region. Research Materials of IMGW, Series: Meteorology 35: 1-68 (in Polish).

Miętus M., Filipiak J., 2004. The temporal and spatial patterns of thermal conditions in the area of the southwestern coast of the Gulf of Gdańsk (Poland) from 1951 to 1998. Int. J. of Climatology 24, 4: 499-509.

Nakicenovic N., Alcamo J., Davis G., de Vries B., Fenhann J., Gaffin S., Gregory K., Grübler A., Jung T.Y., Kram T., La Rovere E.L., Michaelis L., Mori S., Morita T., Pepper W., Pitcher H., Price L., Riahi K., Roehrl A., Rogner H.H., Sankovski A., Schlesinger M., Shukla P., Smith S., Swart R., van Rooijen S., Victor N., Dadi Z., 2000. IPCC Special Report on Emissions Scenarios. Cambridge University Press, Cambridge, United Kingdom and New York, NY, USA.

Roeckner E., Brokopf R., Esch M., Giorgetta M., Hagemann S., Kornblueh L., Manzini E., Schlese U., Schulzweida U., 2006. Sensitivity of simulated climate to horizontal and vertical resolution in the ECHAM5 atmosphere model. J. Climate 19: 3771-3791.

von Storch H., 1995. Inconsistencies at the interface of climate impact studies and global climate research. Meteor. 4: 7280.

von Storch H., 1999. On the use of "inflation" in downscaling. J. Climate 12: 3505-3506.

von Storch H., Zorita E., Cubasch U., 1993. Downscaling of Global Climate Change Estimates to Regional Scales: An Application to Iberian Rainfall in Wintertime. J. Climate 6: 1161-1171.

von Storch H., Zwiers F., 2001. Statistical Analysis in Climate Research. Cambridge Univ. Press. 
Wilby R., Dawson C.W., 2007. SDSM 4.2 - A decision support tool for the assessment of regional climate change impacts. User Manual.

Wilby R.L., Charles SP., Zorita E., Timbal B., Whetton P., Mearns L.O., 2004. Guidelines for Use of Climate Scenarios Developed from Statistical Downscaling Methods. IPCC Task Group on Data and Scenario Support for Impact and Analysis (TGICA).
Wilks D.S., 2008. Statistical Methods in the Atmospheric Sciences. Second Edition. International Geophysics Series 91. Academic Press.

Wilks D.S., 2011. Statistical Methods in the Atmospheric Sciences. Vol. 100. Third Edition (International Geophysics).

Wilks D.S., Wilby R.L., 1999. The weather generation game: a review of stochastic weather models. Progress in Physical Geography 23: 329-357. 